\title{
Quantitative Assessment of Diffusion-Weighted MR Imaging in Patients with Primary Rectal Cancer: Correlation with FDG-PET/CT
}

\author{
Jing Gu, ${ }^{1}$ Pek-Lan Khong, ${ }^{1}$ Silun Wang, ${ }^{1}$ Queenie Chan, ${ }^{2}$ Wailun LAW, ${ }^{3}$ Jingbo Zhang ${ }^{1,4}$ \\ ${ }^{1}$ Department of Diagnostic Radiology, The University of Hong Kong, Hong Kong, China \\ ${ }^{2}$ Philips Healthcare, Philips Electronics Hong Kong Limited, Hong Kong, China \\ ${ }^{3}$ Division of Colorectal Surgery, Queen Mary Hospital, The University of Hong Kong, Hong Kong, China \\ ${ }^{4}$ Department of Diagnostic Radiology, Memorial Sloan-Kettering Cancer Center, C278, 1275 York Avenue, New York, NY 10073, USA
}

\begin{abstract}
Purpose: The aim of the study was to assess correlations between parameters on diffusionweighted imaging and 2-deoxy-2-[18 $\mathrm{F}]$ fluoro-D-glucose-positron emission tomography/computed tomography (FDG-PET/CT) in rectal cancer.

Procedures: Thirty-three consecutive patients with pathologically confirmed rectal adenocarcinoma were included in this study. Apparent diffusion coefficient (ADC) maps were generated to calculate $A D C_{\text {mean }}$ (average $A D C$ ), $A D C_{\text {min }}$ (lowest $A D C$ ), tumor volume, and total diffusivity index (TDI). PET/CT exams were performed within 1 week of magnetic resonance imaging. Standardized uptake values (SUVs) were normalized to the injected FDG dose and body weight.

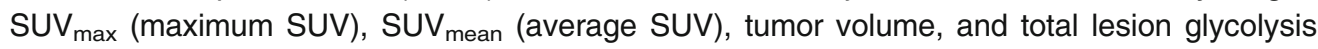
(TLG) were calculated using a $50 \%$ threshold.

Results: Significant negative correlations were found between $\mathrm{ADC}_{\min }$ and $\mathrm{SUV}_{\max }(r=-0.450$, $p=0.009)$, and between $\mathrm{ADC}_{\text {mean }}$ and $\operatorname{SUV}_{\text {mean }}(r=-0.402, p=0.020)$. A significant positive correlation was found between TDI and TLG $(r=0.634, p<0.001)$.

Conclusion: The significant negative correlations between ADC and SUV suggest an association between tumor cellularity and metabolic activity in primary rectal adenocarcinoma.
\end{abstract}

Key words: ADC, DWI, SUV, PET/CT, Primary rectal adenocarcinoma, TDI, TLG

\section{Introduction}

$\mathrm{C}$ olorectal cancer is the second leading cause of cancer death for men and women combined [1], and rectal cancer constitutes about one third of cases. Magnetic resonance imaging (MRI) has the advantages of superior soft tissue contrast and multiplanar imaging capability, thus often considered particularly useful for local staging. On the other hand, 2-deoxy-2-[ $\left.{ }^{18} \mathrm{~F}\right]$ fluoro-D-glucose-positron emission tomography/computed tomography (FDG-PET/CT) is being more and more commonly used for detecting distant

Correspondence to: Jingbo Zhang; e-mail: Zhangj12@mskcc.org metastases and providing systemic staging of patients with rectal cancer.

Recent studies show that both MRI and PET have the capability of providing important functional information for tumor, in addition to the above-mentioned staging capacity. For example, with advances in MR technology and the use of faster, more robust sequences, diffusionweighted imaging (DWI), an established diagnostic technique in neuroimaging, has shown great potential for evaluation of tumors in the body as well [2]. DWI is used to measure the Brownian motion of water molecules in tissue, which has been shown to be inversely proportional to cellular density [3], presumably because 
increased cellular density limits water diffusion in the interstitial space. The apparent diffusion coefficient (ADC), a quantitative parameter measured on DWI, has been shown to be useful for evaluating solid tumors in the abdomen and pelvis [4, 5]. It has been suggested that ADC may provide useful information regarding tumor cellularity [6], tumor aggressiveness [7], subtype characterization [8], and cancer treatment response [2, 9, 10]. However, the experience of applying DWI in evaluation of rectal cancer is relatively limited. It has been shown that DWI can improve detection of rectal cancer when combined with T2-weighted images [11] and may have a potential role in predicting tumor response to therapy $[12,13]$.

FDG-PET is capable of imaging tumors based on their increased glucose metabolism. FDG uptake on PET, quantified by the standardized uptake value (SUVs), is a useful marker for the level of tumor metabolic activity. It has been reported that high SUV is correlated with rapid cellular proliferation in breast, lung, and ovarian cancers [14-16]. A number of studies demonstrated the relationship between higher FDG uptake and a more aggressive course of the malignancy [17, 18]. Meanwhile, the role of PET/CT to assess treatment response has been established in multiple types of tumors [19, 20]. In rectal cancer imaging, PET/CT has been suggested as an accurate technique in the detection or staging of newly diagnosed or recurrence rectal cancer $[21,22]$. Furthermore, qualitative assessment of FDG-PET provides useful information of treatment response and prognostic information in patients with rectal cancer [23, 24].

Even though both DWI and PET/CT have been used in various aspects of tumor evaluation, including detection, characterization, and treatment response assessment, to our knowledge, the relationship between ADC and SUV has not been explored in rectal cancer. Since both ADC and SUV values have been associated with biological aggressiveness and treatment response in certain tumors including rectal cancer, we hypothesize that SUV values which reflect metabolic activity may have correlation with ADC values which reflect cellular density in rectal cancer. Thus, the aim of this study was to assess the correlations between quantitative parameters on DWI and PET in primary rectal cancer.

\section{Materials and Methods}

\section{Patients}

Between November 2008 and June 2009, 33 consecutive patients (19 men, 14 women, 45-88 years old) with newly diagnosed and pathologically confirmed rectal adenocarcinoma and having undergone both MRI and PET/CT examinations were included in this study. All patients underwent both MRI and PET/CT scans within 1 week (mean time interval, $2 \pm 1$ day). This study was approved by Institutional Review Board, and informed consent was obtained from all patients. This study was also compliant with the patient confidentiality regulations.

\section{Acquisition of MR Images}

All MR examinations were performed on a 3-T scanner (Achieva; Philips Healthcare) with the patients in supine position. Routine T2-weighted, T1-weighted, DWI, and contrast-enhanced sequences were obtained. Turbo spin echo T2-weighted images were obtained in three planes using the following parameters: transverse, $\mathrm{TR} / \mathrm{TE}=$ $1,862 / 99 \mathrm{~ms}$, field of view $($ FOV $)=19 \times 23 \mathrm{~cm}$, matrix size $=272 \times$ 318 , slice thickness $=6 \mathrm{~mm}$, gap $=0$, number of acquisition $=1$, sense factor $=1.5$; coronal, TR/TE $=2,800 / 100 \mathrm{~ms} ; \mathrm{FOV}=25 \times 26 \mathrm{~cm}$, matrix size $=416 \times 373$, slice thickness $=5 \mathrm{~mm}$, gap $=0.5 \mathrm{~mm}$, number of acquisition $=1$, sense factor $=1.5$; sagittal, $\mathrm{TR} / \mathrm{TE}=$ $2,800 / 100 \mathrm{~ms}, \mathrm{FOV}=23 \times 24 \mathrm{~cm}$, matrix size $=328 \times 341$, slice thickness $=5 \mathrm{~mm}$, gap $=0$, number of acquisition $=1$, sense factor $=$ 1. Axial TSE T1-weighted images were obtained using the following parameters: $\mathrm{FOV}=23 \times 38 \mathrm{~cm}$, matrix size $=236 \times 314$, slice thickness $=7 \mathrm{~mm}$, gap $=1 \mathrm{~mm}$, number of acquisition $=1$, sense factor $=1$. Transverse free-breathing DWI was obtained by using a single-shot multi-slice echo planar imaging (EPI) sequence with short TI inversion recovery (STIR) fat-suppression and sliceselection gradient reversal technique [25] with the following parameters: $\mathrm{TR} / \mathrm{TE}=7,036 / 48 \mathrm{~ms}, \mathrm{FOV}=40 \times 33 \mathrm{~cm}$, matrix size $=$ $188 \times 159$, slice thickness $=5 \mathrm{~mm}$, gap $=0$, number of acquisitions $=$ 4 , sense factor $=2, b$ value $=0$ and $1,000 \mathrm{~s} / \mathrm{mm}^{2}$. The acquisition time for DWI was approximately $4 \mathrm{~min}$. Transverse single-shot TSE T2-weighted images were then obtained with slice locations identical to those of transverse DWI for image fusion (OsiriX Medical Imaging Software, version 3.5, Switzerland), using the following parameters: TR/TE $=891 / 98 \mathrm{~ms}, \mathrm{FOV}=40 \times 33 \mathrm{~cm}$, matrix size $=332 \times 125$, slice thickness $=5 \mathrm{~mm}$, gap $=0$, number of acquisitions $=1$. Subsequently fast field echo (FFE) T1-weighted images were obtained before and after administration of intravenous contrast. Flex-L coil with using SENSE technique was placed over the pelvis to reduce gas effect to imaging quality. Patients were asked to fast for $4 \mathrm{~h}$ before MR.

After image acquisition, pixel-to-pixel ADC map was reconstructed using the standard software on the imaging console (Achieva; Philips Healthcare).

\section{Acquisition of PET/CT Images}

All PET/CT examinations were performed on a PET/CT scanner (Discovery VCT, GE Healthcare Bio-Sciences Corp.). All patients fasted with hydration $6 \mathrm{~h}$ before receiving intravenous injection of FDG at $4.8 \mathrm{MBq} / \mathrm{kg}$ body weight. PET/CT scans were performed 60 min after the injection of the FDG. A whole body emission PET scan with a $70-\mathrm{cm}$ axial FOV, a $218 \times 218$ matrix, and $3.27 \mathrm{~mm}$ thickness was obtained with five bed positions within $20 \mathrm{~min}$. CT images were performed using the following scan parameters: $\mathrm{FOV}=$ $50 \mathrm{~cm}$, matrix $=512 \times 512$, collimation $=0.625 \mathrm{~mm} \times 64$, pitch $=0.984$, gantry rotation speed $=0.5 \mathrm{~s}$, tube voltage $=120 \mathrm{kVp}$, and tube current $=$ 200-400 mA. The use of intravenous contrast for CT was at the discretion of the ordering physician. LASIX (4 mg) was administered intravenously to fill the bladder to reduce artifacts from high ${ }^{18} \mathrm{~F}$-FDG activity in urine. Attenuation correction was performed on PET images with CT data using an ordered-subset expectation maximization 
iterative reconstruction algorithm (14 subsets and two iterations) [26]. The CT images were then reconstructed at 2.5-mm intervals to fuse with the PET images (Advanced Workstation 4.3, GE Healthcare).

\section{Image Analysis}

For ADC measurement, regions of interest (ROIs) were manually drawn along contours of each tumor on ADC maps on every slice covering the entire tumor by an investigator (J. G., with 3 years of experience in reading and performing volumetric tumor measurements on body MRI) who was blinded to PET/CT images and all clinical information other than that the patient was diagnosed with rectal cancer.

Mean $\mathrm{ADC}$ value $\left(\mathrm{ADC}_{i}\right)$ and the cross-sectional area $\left(\mathrm{area}_{i}\right)$ of the tumor ROI on each slice ( $i$ representing the slice number) was calculated by Image J software (NIH, USA). Subsequently, $\mathrm{ADC}_{\text {mean }}$ of the entire tumor was calculated as the weighted average for all $\mathrm{ADC}_{\mathrm{i}}$ values in each tumor by Eq. 1:

$$
\mathrm{ADC}_{\text {mean }}=\frac{\sum_{i}\left(\mathrm{ADC}_{i} \times \mathrm{Area}_{i}\right)}{\sum_{i} \mathrm{Area}_{i}}
$$

We calculated weighted averages because this would be mathematically identical to calculating averages of ADC values directly from all voxels within the entire tumor volume. $\mathrm{ADC}_{\mathrm{min}}$ was also determined as the lowest ADC value among all voxels in each tumor. Ratio of ADC (rADC) was then calculated as $\mathrm{ADC}_{\min } /$ $\mathrm{ADC}_{\text {mean }}$, which showed a significant correlation with $\mathrm{SUV}_{\max } /$ $\mathrm{SUV}_{\text {mean }}$ ratio (rSUV) in cervical cancers [27]. Volume of the rectal tumor on DWI images was calculated by Eq. 2:

$$
V_{\text {DWI }}=\sum_{i} \text { Area }_{i} \times(\text { thickness }+ \text { gap })
$$

We also introduced the concept of total diffusivity index (TDI), which is the sum of 1/ADC among all the voxels in a tumor calculated by home-made MATLAB script using Eq. 3, as a corresponding value to total lesion glycolysis (TLG) measured from PET:

$$
\mathrm{TDI}=V_{\mathrm{DWI}} \times \frac{\sum_{i}\left(D_{i} \times \text { Area }_{i}\right)}{\sum_{i} \text { Area }_{i}}
$$

where $V_{\text {DWI }}$ is calculated by Eq. 2; where $D$ is the mean $1 /$ ADC for all voxels on each ROI area. This equation would be mathematically identical to calculating sums of $1 / \mathrm{ADC}$ values directly from all voxels within the entire tumor volume.

For SUV measurement, the PET, CT, and fused PET/CT images were displayed on a workstation (Advanced Workstation, 4.3, GE Healthcare), and a 3D ROI was placed over the entire tumor by an investigator (J. Z., with 2 years of experience in interpreting PET/ CT) who was blinded to MRI images, and all clinical information other than that the patient was diagnosed with rectal cancer.
Maximum standardized uptake value $\left(\mathrm{SUV}_{\max }\right)$, mean standardized uptake value $\left(\mathrm{SUV}_{\text {mean }}\right)$, volume of tumor, and TLG were automatically calculated by the workstation. SUV was defined by Eq. 4:

$\mathrm{SUV}=\frac{\text { measured radioactivity concentration }[\mathrm{Bq} / \mathrm{mL}]}{\text { injected radioactivity }[\mathrm{Bq}] /(\text { bodyweight }[\mathrm{kg}] \times 1,000)}$

$\mathrm{SUV}_{\max }$ was defined as the highest value of SUV among all voxels within the 3D ROI placed over the rectal tumor. Subsequently, a fixed threshold value of $50 \%$ of the maximum uptake was used to determine tumor margins automatically, and the tumor volume $\left(V_{\mathrm{PET}}\right)$ was calculated by the workstation accordingly [22]. The $\mathrm{SUV}_{\text {mean }}$ was then measured as the average of SUV values in all voxels within the threshold-defined tumor volume. rSUV was then calculated as $\mathrm{SUV}_{\max } / \mathrm{SUV}_{\text {mean }}$. TLG was calculated using Eq. 5:

$$
\mathrm{TLG}=V_{\mathrm{PET}} \times \mathrm{SUV}_{\text {mean }}
$$

\section{Clinical Correlation}

All patients had biopsy under colonoscopy that confirmed histopathological diagnosis of rectal cancer before the imaging examinations were performed (mean time interval, $15 \pm 4$ days). Circulating plasma level of carcinoembryonic antigen (CEA) was obtained within 2 weeks of MRI scan (mean time interval, $9 \pm$ 3 days). Based on the references from our institution, CEA> $5.0 \mathrm{mg} / \mathrm{mL}$ was regarded as abnormal.

\section{Statistical Analysis}

All results were expressed as mean \pm standard deviation (SD). Pearson's correlation test was used to detect the relationships between quantitative indices of DWI and PET. Bland-Altman plot was performed to assess agreement between volumes measured on DWI and PET. One-way ANOVA test was used to analyze differences of SUV and ADC values in terms of well, moderate, or poorly differentiated rectal cancer. A $p$ value of $<0.05$ was considered to indicate statistical significance. All statistical analyses were performed using SPSS software package (SPSS, Version 16.0.1, Chicago, IL, USA).

\section{Results}

\section{Patient and Lesion Characteristics}

Among the 33 patients included in this study, 19 were men and 14 were women. They had a mean age of 67 years (standard deviation, 11 years; range, $45-88$ years). All patients were confirmed to have rectal adenocarcinomas by pathological evaluations. Characteristics of study subjects are shown in Table 1.

$\mathrm{ADC}_{\text {min }}$ and $\mathrm{ADC}_{\text {mean }}$ for all tumors were $0.35 \pm 0.15 \times$ $10^{-3} \mathrm{~mm}^{2} / \mathrm{s}$ (range, $0.10 \sim 0.75 \times 10^{-3} \mathrm{~mm}^{2} / \mathrm{s}$ ) and $0.85 \pm$ 
Table 1. Characteristics of patients and lesions

\begin{tabular}{ll}
\hline Patient characteristics & \\
Age & $67 \pm 11$ years \\
Gender & Female $(n=14)$, male $(n=19)$ \\
Serum CEA level & $34.4 \pm 69.7 \mathrm{mg} / \mathrm{mL}$ \\
Patients with normal CEA $(\leq 5.0 \mathrm{mg} / \mathrm{mL})$ & $20(60.6 \%)$ \\
Patients with abnormal CEA $(>5.0 \mathrm{mg} / \mathrm{mL})$ & $13(39.4 \%)$ \\
Pathological diagnosis & Number of lesions $(\%)$ \\
Well-differentiated adenocarcinoma & $10(30 \%)$ \\
Moderately differentiated adenocarcinoma & $14(42 \%)$ \\
Poorly differentiated adenocarcinoma & $9(27 \%)$ \\
Clinical staging & Number of patients $(\%)$ \\
Stage I & $1(3 \%)$ \\
Stage II & $5(15 \%)$ \\
Stage III & $24(73 \%)$ \\
Stage IV & $3(9 \%)$ \\
\end{tabular}

$0.24 \times 10^{-3} \mathrm{~mm}^{2} / \mathrm{s}$ (range, $0.43 \sim 1.5 \times 10^{-3} \mathrm{~mm}^{2} / \mathrm{s}$ ), respectively. rADC was $0.42 \pm 0.15$ (range, $0.12 \sim 0.67$ ). TDI was $27.25 \pm 30.64 \times 10^{3} \mathrm{~ms}$ (range, $2.54 \sim 175.01 \times 10^{3} \mathrm{~ms}$ ). Tumor volume measured by DWI was $22.6 \pm 24.5 \mathrm{~cm}^{3}$ (range $2.87 \sim 135.8 \mathrm{~cm}^{3}$ ). Fig. 1 demonstrates the measurement of ADC values and tumor volume on DWI in a typical case.
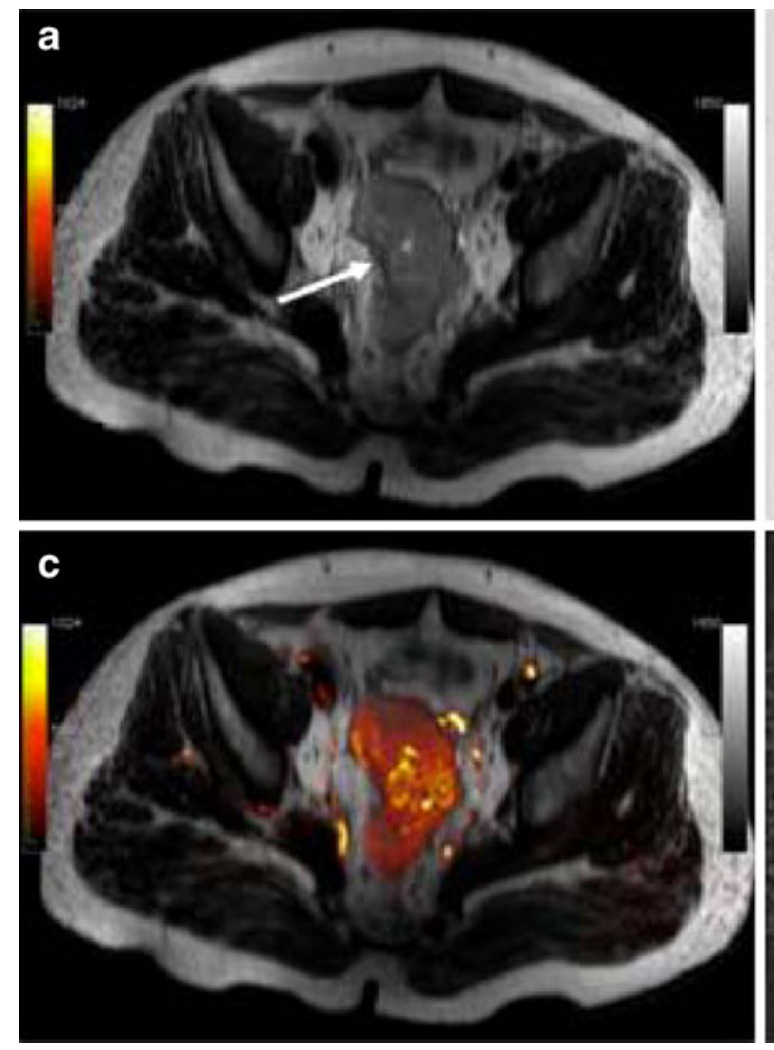

$\mathrm{SUV}_{\text {max }}$ and $\mathrm{SUV}_{\text {mean }}$ values were $10.55 \pm 5.26$ (range, $4.10 \sim 26.10$ ) and $6.94 \pm 3.56$ (range, $2.70 \sim 17.5$ ), respectively. rSUV was $0.65 \pm 0.04$ (range, $0.54 \sim 0.73$ ). TLG of all tumors was $99.8 \pm 98.7 \mathrm{~g}$ (range, 8.5 386.5 g). Tumor volume measured by PET/CT was $15.0 \pm 12.0 \mathrm{~cm}^{3}$ (range $2.4 \sim 64.5 \mathrm{~cm}^{3}$ ), using $50 \%$ of $\mathrm{SUV}_{\max }$ as threshold. Fig. 2 demonstrates the measurement of SUV, TLG, and tumor volume on $\mathrm{PET} / \mathrm{CT}$ in a typical case.

\section{Correlations Between ADC and SUV}

Significant negative correlations were found between $\mathrm{ADC}_{\text {min }}$ and $\mathrm{SUV}_{\text {max }}\left(r=-0.450, p=0.009, \mathrm{SUV}_{\text {max }}=-15.825 \mathrm{ADC}_{\min }+\right.$ 16.081), and $\mathrm{ADC}_{\text {mean }}$ and $\mathrm{SUV}_{\text {mean }}(r=-0.402, p=0.020$, $\left.\mathrm{SUV}_{\text {mean }}=-5.884 \mathrm{ADC}_{\text {mean }}+11.948\right)$ (Fig. 3). The correlation between $\mathrm{rADC}$ and $\mathrm{rSUV}$ was weak $(r=-0.161, p=0.370)$.

\section{Correlations Between TDI and TLG}

Significant correlation was found between TDI and TLG $(r=$ $0.634, p<0.001, \mathrm{TLG}=2.044 \mathrm{TDI}+44.114$ ).
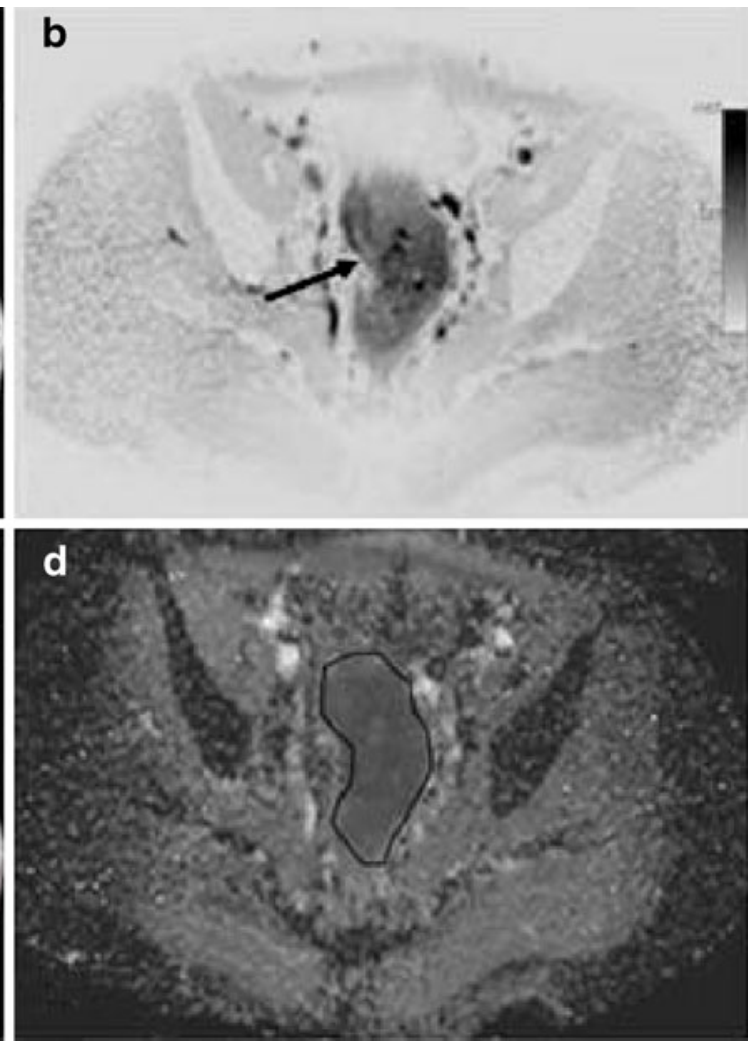

Fig. 1. MRI images of a 55-year-old man with moderately differentiated rectal adenocarcinoma. a Axial single-shot TSE T2weighted image of the pelvis shows a large rectal mass (arrow). $\mathbf{b}$ Axial DWI image of the pelvis at the same slice location as a is shown with inverted gray scale to demonstrate a PET-like image of the rectal mass (arrow). c Fused image from $\mathbf{a}$ and $\mathbf{b}$ can be performed for easy viewing if desired. $\mathbf{d}$ On the $A D C$ map generated from $\mathbf{b}$, an ROI was manually drawn along the contour of the tumor (black line). Subsequently, $A D C_{\text {mean }}, A D C_{\text {min }}$, and the cross-sectional area of the tumor on this image were calculated by ImageJ software. 

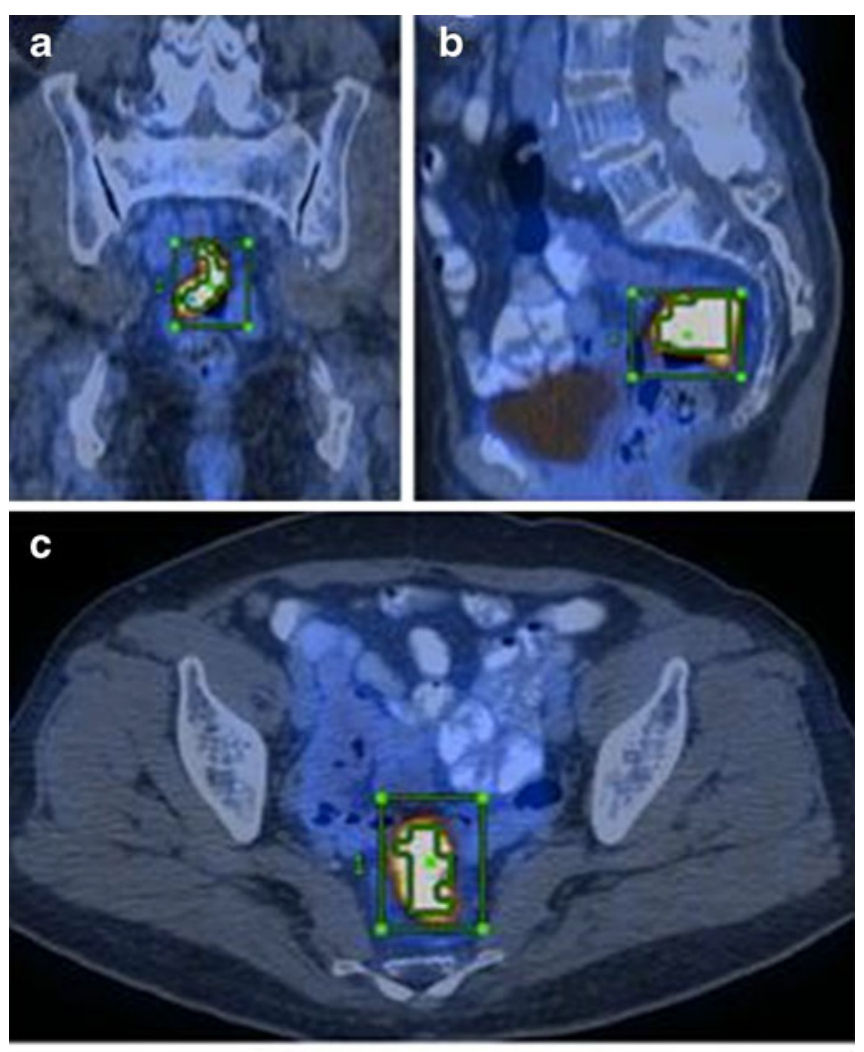

d

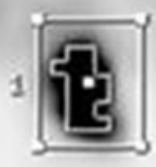

Fig. 2. PET/CT images of an 82-year-old woman with moderately differentiated rectal adenocarcinoma. a-c Fused $\mathrm{PET} / \mathrm{CT}$ images in coronal and sagittal reformatted planes, as well as in the axial plane show a hypermetabolic lesion in the rectum. A 3D ROI (green box) was placed to cover the entire lesion on the Advanced AW Workstation. d From the corresponding PET images, SUV max $_{\text {was }}$ measured. Subsequently, SUV $\mathrm{V}_{\text {mean }}$, tumor volume, and TLG were calculated automatically using a threshold of $50 \%$ SUV $_{\max }$.

\section{Agreement Between Tumor Volumes Measured on MR and PET}

A Bland-Altman plot analysis, which is used to compare the mean of the differences and limits of agreement (average difference \pm 1.96 standard deviation of the difference) between two methods, showed good agreement between tumor volumes measured on DWI and PET (Fig. 4).
However, by average, by using the standard $50 \%$ threshold, PET underestimated the rectal cancer volume compared with DWI.

\section{Correlations Between Imaging Parameters and Cell Differentiation of Rectal Cancer}

Table 2 shows SUV and ADC values in well-differentiated, moderately differentiated, and poorly differentiated rectal cancers respectively. Although there was a trend of having higher SUV and lower $\mathrm{ADC}_{\text {min }}$ values in the poorly differentiated tumors, these differences did not reach statistical significance. However, this could be related with a suboptimal statistical power associated with the relatively small patient population in this study.

\section{Discussion}

Both DWI and PET/CT are established imaging modalities in tumor assessment. It has been shown that tumors often demonstrate decreased ADC on DWI, and increased SUV on FDG-PET. In addition, ADC and SUV have both been shown to correlate with tumor characteristics and response to treatment. Therefore, we undertook this study to assess the relationship between quantitative parameters measured on DWI and PET in primary rectal cancer.

First, we found significant negative correlations between ADC and SUV values in rectal cancer. SUV values are quantitative indices provided by PET/CT and represent the activity concentration in tumor tissue normalized to the injected FDG dose and body weight of the patient. Intravenous injected FDG is transported across the cell membrane by glucose transporters (Gluts) and accumulated in metabolically active tumor cells. SUV values have correlation with tumor cellular density as well as the grade and the differentiation of some tumors and can aid in detection, characterization, prognostication, and monitoring treatment response of malignancy $[17,28-33]$. SUV correlated significantly with cellular density in non-small cell lung cancer [32]. In astrocytomas, Herholz et al. [31] found that glucose consumption correlated significantly with cell density which is a major determinant of glucose consumption in astrocytomas. In rectal cancer, tumor size and depth of invasion of rectal cancer were significantly correlated with SUV [30]. On the other hand, ADC is a quantitative parameter provided by DWI and reflects water diffusion in tissue. There is decreased ADC in tumor tissue due to increased diffusion barrier from tumor cell membrane. ADC has been regarded as a useful imaging marker to reflect tumor cell density and to distinguish different tissue compartments in early, intermediate, and advanced tumor stages $[34,35]$. Variation of ADC has been used to monitor changes in the biological structure of tumor tissue during tumor progression. In early stages of tumor development, tumors appeared homogeneous and have lower ADC values. In contrast, there is an increased ADC that correlated well 

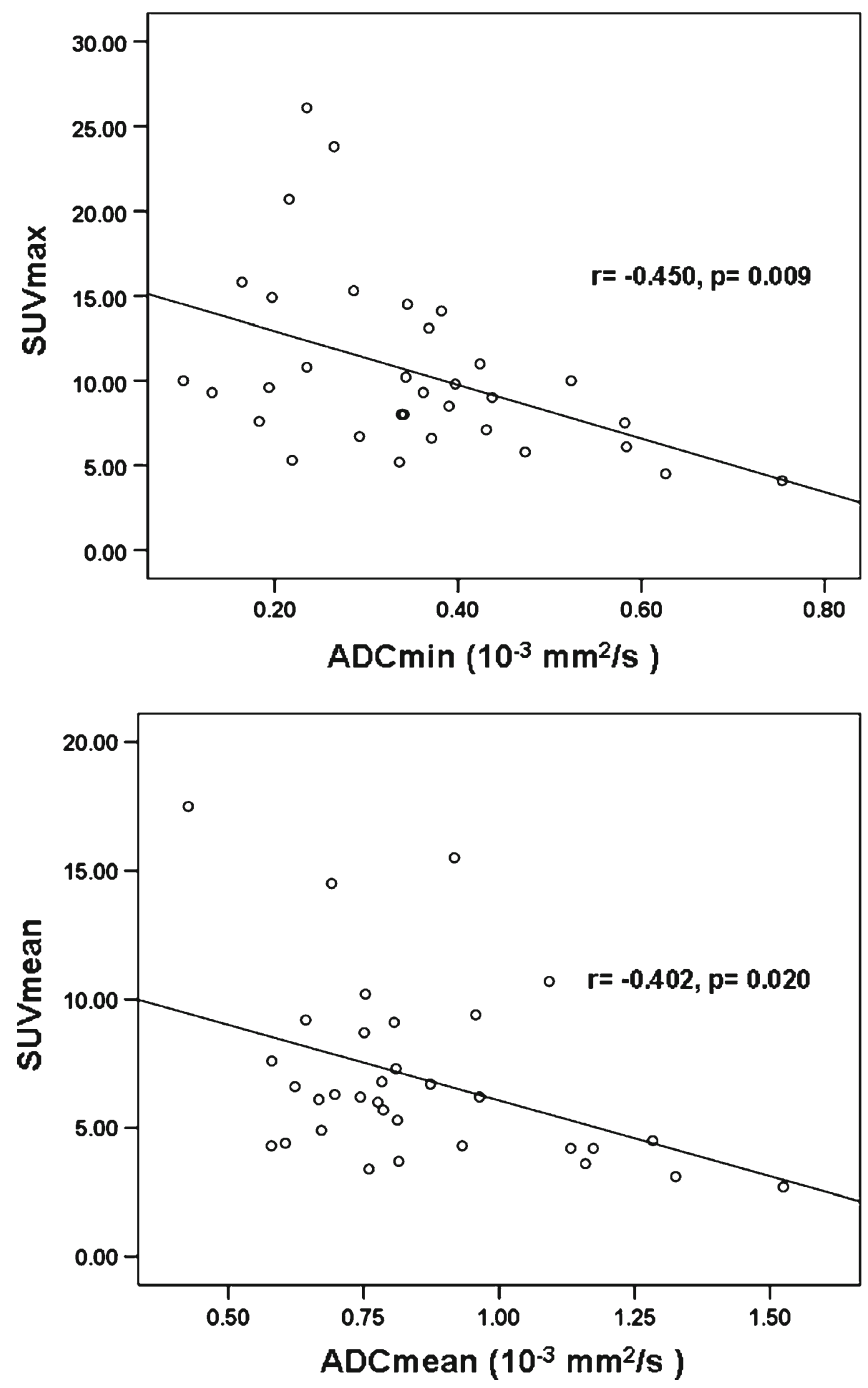

Fig. 3. Scatter plots show the significant negative correlations between $\mathrm{ADC}_{\text {min }}$ and $\mathrm{SUV}_{\text {max }}(\mathbf{a}), \mathrm{ADC}_{\text {mean }}$, and SUV mean (b).

with areas of necrosis (reduced cell density) in intermediate and advanced tumor stage [34]. Although a significant correlation between tumor FDG uptake and tumor cellular density was found in some studies $[16,36]$, there is limited information about the relationship between SUV and ADC. Ho et al. made an important attempt but did not find significant correlations between $\mathrm{SUV}_{\max }$ and $\mathrm{ADC}$ values in cervical cancer [27]. There may be several potential causes for this discrepancy. One is that imaging parameters may very well have different diagnostic performances for different types of tumors (cervical versus rectal cancer). Another potential cause is that mixed pathological types were present in Ho's study on cervical cancer patients, including squamous cell carcinoma, adenocarcinoma, and adenosquamous carcinoma. The mixed pathologies may conceivably lead to obscuration of an underlying correlation. In addition, Ho et al. calculated $\mathrm{ADC}_{\text {mean }}$ by taking averages of mean $\mathrm{ADC}$ values for each image, regardless of the

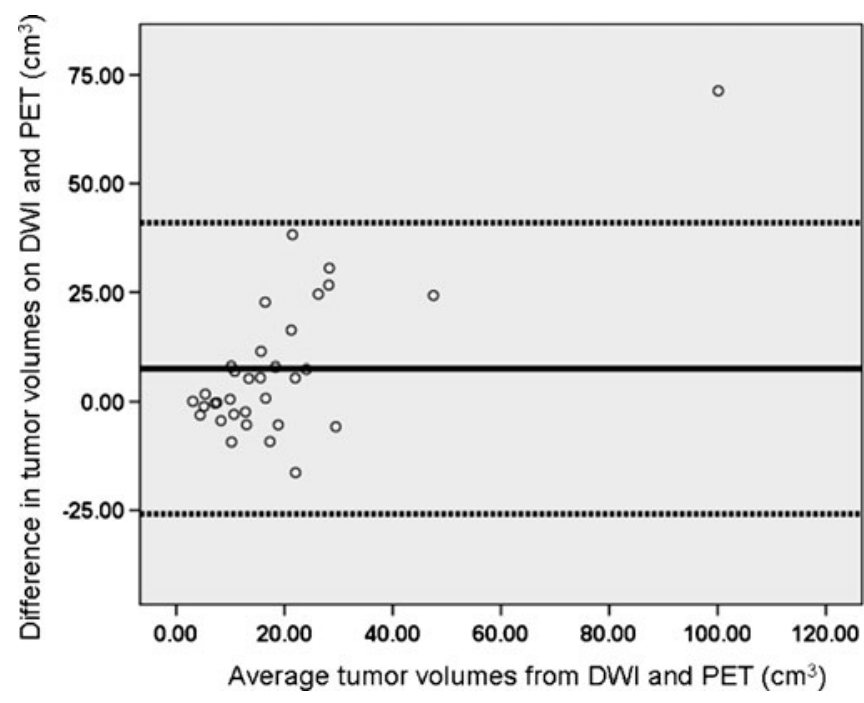

Fig. 4. A Bland-Altman plot analysis shows a high correlation of volumes detected by DWI and PET/CT. $X$ axis indicates the average tumor volumes measured by DWI and PET. $Y$ axis indicates the difference in tumor volumes on DWI and PET. The solid horizontal line reflects the bias between the two measurements. The two dash lines denote $95 \%$ limit of agreement (mean difference $\pm 1.96 \times \mathrm{SD}$ ).

cross-sectional size of the tumor on each image [27]. We feel that a weighted average taking into consideration of the tumor cross-sectional size on each image is a more accurate calculation to reflect true mean ADC value of all voxels in the entire tumor.

We also found that TDI values, defined as the sum of $1 /$ ADC among all the voxels in a tumor, showed a significant correlation with TLG, which is the sum of SUV among all the voxels in a tumor. TLG reflects the total amount of glycolysis in a given tumor and has been used clinically as a surrogate biomarker for monitoring treatment response [37-39]. For example, Guillem et al. found that a reduction of $30.5 \%$ of TLG in rectal cancer could predict no-evidence-of-disease status and freedom from recurrence with a sensitivity of $90 \%$ and specificity of $80 \%$ [38]. The correlation between TDI and TLG is not surprising, as the ADC and SUV values, as well as the tumor volumes measured by MR and PET, are correlated. Since tumor's response to treatment may be reflected in changes of both size and function, we feel that TDI values may have a potential role in monitoring treatment response similar to TLG. However, longer-term studies with bigger patient populations would be helpful to validate this.

In terms of correlation between the imaging parameters and tumor pathologic characteristics, we did see a trend of higher SUV values and lower ADC values in the more poorly differentiated rectal tumors. This is not surprising given that less differentiated tumors metabolize more glucose for energy production and grow more rapidly. 
Table 2. Imaging parameters and tumor differentiation

\begin{tabular}{llrr}
\hline & Well differentiated & Moderately differentiated & Poorly differentiated \\
\cline { 2 - 3 } & \multicolumn{1}{l}{$n=10$} & $n=14$ & $n=9$ \\
\hline $\mathrm{SUV}_{\text {max }}$ & $9.01 \pm 4.44$ & $11.18 \pm 6.00$ & $11.30 \pm 5.08$ \\
$\mathrm{SUV}_{\text {mean }}$ & $5.88 \pm 2.92$ & $7.31 \pm 4.15$ & $7.52 \pm 3.33$ \\
$\mathrm{ADC}_{\text {min }}\left(\times 10^{-3} \mathrm{~mm}^{2} / \mathrm{s}\right)$ & $0.34 \pm 0.16$ & $0.40 \pm 0.15$ & 0.55 \\
$\mathrm{ADC}_{\text {mean }}\left(\times 10^{-3} \mathrm{~mm}^{2} / \mathrm{s}\right)$ & $0.89 \pm 0.25$ & $0.84 \pm 0.30$ & 0.54 \\
\hline
\end{tabular}

However, the differences between poorly, moderately, and well-differentiated rectal tumors did not reach statistical significance. It is possible that the relative small patient population in our study may have lead to suboptimal statistical powers. Larger studies in the future would be helpful to further evaluate these potential correlations. Another possible reason is that FDG-PET might be insensitive in showing mucinous carcinomas because of the low cellularity of these tumors caused by presence of mucin which is commonly found in colonic tumors [40]. Significantly lower FDG uptake was found in bronchioloalveolar cell carcinoma, which often contains abundant mucin, compared with adenocarcinoma, in which positive correlation was found between FDG uptake and the degree of cell differentiation [41, 42]. On the other hand, one study showed high ADC value in poorly differentiated rectal adenocarcinoma, including mucinous carcinoma and signet ring cell carcinoma [43]. And no overt correlation was found between $\mathrm{ADC}$ and cell differentiation due to a lot of mucin contained in the rectal adenocarcinoma [43].

In terms of measuring tumor volume on MR, although T2-weighted images are considered to provide superior anatomic details, we measured tumor volume on ADC maps, so that the calculation of TDI would be solely based on parameters generated from DWI images. A high correlation of volumes detected by DWI and PET/CT was demonstrated in the Bland-Altman plot. In Fig. 4, the outlying data point on the right upper corner represented a large tumor with MRI volume of $135 \mathrm{~cm}^{3}$, which was vastly underestimated in volume on PET $\left(64.5 \mathrm{~cm}^{3}\right)$ when $50 \%$ threshold was used, presumably due to an unusual distribution of SUV values in the tumor voxels. If a $30 \%$ threshold was used, the tumor volume on PET would have been $142 \mathrm{~cm}^{3}$. Moreover, by average, tumor volumes measured on DWI was $7.6 \mathrm{~cm}^{3}$ greater than those measured on PET in this study. Similar findings have been reported in the literature. Daisne et al. compared the diagnostic accuracy of measuring head and neck tumor volumes by different imaging modalities including CT, PET, and MRI [44]. They found that PET provided the smallest tumor volumes among the three modalities. The smallest tumor volumes on PET may be related to the value of threshold used for automated tumor volume measurement. In this study, we used a threshold of $50 \% \mathrm{SUV}_{\max }$ to automatically determine tumor boundary on PET. Usually, $40 \%$ or $50 \%$ threshold is suggested to evaluate rectum cancer by PET [22]. However, currently, there is no clinical consensus as to what threshold can provide accurate information of tumor boundary [45, 46], and it is possible that different types of tumors may require different thresholds. It has been suggested that using an optimal SUV threshold on PET may provide more accurate estimation of tumor volume, with the optimal threshold being defined as the threshold at which PET shows a similar tumor volume compared with CT or MRI [27].

With fast imaging techniques such as EPI and parallel imaging techniques [47], DWI can be performed with diagnostic quality at high $b$ values in the body [9], which lead to heightened interests in investigating its role in body and oncologic imaging. Takahara et al. developed the concept of diffusion-weighted whole body imaging with background body signal suppression (DWIBS) and introduced the feasibility of free-breathing DWI combined with STIR-EPI techniques [48]. In our study, a similar technique was used, with additional slice-selection gradient reversal technique to aid in more complete suppression of the fat signal. Due to good background body signal suppression, DWIBS can produce PET-like images, which has been widely used for oncologic imaging. However, with the longer survival rate seen in many tumor patients due to improved clinical care, patients will get more and more radiation exposure from surveillance imaging studies such as PET/CT. In addition, the contrast injections for both PET and CT are associated with certain complications, although relatively rare. Therefore, if DWI parameters such as ADC values can be validated clinically for accurate tumor assessment, whole-body MR techniques such as DWIBS may provide a safe alternative imaging modality for the oncologic patient.

There are certain limitations to our study. First, the number of subjects in our study is relatively small. However, we found some significant correlations between MR and PET parameters despite the relatively small sample size. Second, although imaging correlations were demonstrated in this current study, pathological evidence, such as measurements of cellularity, Gluts, and hexokinase, is lacking to support our findings. Thirdly, imaging parameters may have different diagnostic performances for different types of tumors. Therefore, the correlations we found in rectal adenocarcinomas may not be transferrable to other types of tumors, and each tumor type should be tested individually. 


\section{Conclusion}

Our results indicate that DWI parameters such as ADC and TDI are correlated with PET parameters such as SUV and TLG in primary rectal cancer. Future larger clinical trials in a variety of tumors would be helpful to confirm our preliminary findings and further determine the roles of ADC and TDI in oncologic imaging.

Conflict of interest. The authors declare that they have no conflict of interest.

Open Access. This article is distributed under the terms of the Creative Commons Attribution Noncommercial License which permits any noncommercial use, distribution, and reproduction in any medium, provided the original author(s) and source are credited.

\section{References}

1. Jemal A, Siegel R, Ward E, Hao Y, Xu J, Murray T et al (2008) Cancer statistics, 2008. CA Cancer J Clin 58:71-96

2. Dudeck O, Zeile M, Pink D, Pech M, Tunn PU, Reichardt P et al (2008) Diffusion-weighted magnetic resonance imaging allows monitoring of anticancer treatment effects in patients with soft-tissue sarcomas. J Magn Reson Imaging 27:1109-1113

3. Guo AC, Cummings TJ, Dash RC, Provenzale JM (2002) Lymphomas and high-grade astrocytomas: comparison of water diffusibility and histologic characteristics. Radiology 224:177-183

4. Taouli B, Vilgrain V, Dumont E, Daire JL, Fan B, Menu Y (2003) Evaluation of liver diffusion isotropy and characterization of focal hepatic lesions with two single-shot echo-planar MR imaging sequences: prospective study in 66 patients. Radiology 226:71-78

5. Zhang J, Tehrani YM, Wang L, Ishill NM, Schwartz LH, Hricak H (2008) Renal masses: characterization with diffusion-weighted MR imaging - a preliminary experience. Radiology 247:458-464

6. Hayashida Y, Hirai T, Morishita S, Kitajima M, Murakami R, Korogi Y et al (2006) Diffusion-weighted imaging of metastatic brain tumors: comparison with histologic type and tumor cellularity. AJNR Am J Neuroradiol 27:1419-1425

7. Kanauchi N, Oizumi H, Honma T, Kato H, Endo M, Suzuki J et al (2009) Role of diffusion-weighted magnetic resonance imaging for predicting of tumor invasiveness for clinical stage IA non-small cell lung cancer. Eur J Cardiothorac Surg 35:706-710

8. Taouli B, Thakur RK, Mannelli L, Babb JS, Kim S, Hecht EM et al (2009) Renal lesions: characterization with diffusion-weighted imaging versus contrast-enhanced MR imaging. Radiology 251:398-407

9. Koh DM, Collins DJ (2007) Diffusion-weighted MRI in the body: applications and challenges in oncology. AJR Am J Roentgenol 188:1622-1635

10. Sharma U, Danishad KK, Seenu V, Jagannathan NR (2009) Longitudinal study of the assessment by MRI and diffusion-weighted imaging of tumor response in patients with locally advanced breast cancer undergoing neoadjuvant chemotherapy. NMR Biomed 22:104-113

11. Rao SX, Zeng MS, Chen CZ, Li RC, Zhang SJ, Xu JM et al (2008) The value of diffusion-weighted imaging in combination with T2-weighted imaging for rectal cancer detection. Eur J Radiol 65:299-303

12. Hein PA, Kremser C, Judmaier W, Griebel J, Pfeiffer KP, Kreczy A et al (2003) Diffusion-weighted magnetic resonance imaging for monitoring diffusion changes in rectal carcinoma during combined, preoperative chemoradiation: preliminary results of a prospective study. Eur $\mathbf{J}$ Radiol 45:214-222

13. Kremser C, Judmaier W, Hein P, Griebel J, Lukas P, de Vries A (2003) Preliminary results on the influence of chemoradiation on apparent diffusion coefficients of primary rectal carcinoma measured by magnetic resonance imaging. Strahlenther Onkol 179:641-649

14. Nakamoto Y, Saga T, Fujii S (2005) Positron emission tomography application for gynecologic tumors. Int J Gynecol Cancer 15:701-709

15. Ueda S, Kondoh N, Tsuda H, Yamamoto S, Asakawa H, Fukatsu K et al (2008) Expression of centromere protein F (CENP-F) associated with higher FDG uptake on PET/CT, detected by cDNA microarray, predicts high-risk patients with primary breast cancer. BMC Cancer 8:384-396
16. Vesselle H, Schmidt RA, Pugsley JM, Li M, Kohlmyer SG, Vallires E et al (2006) Lung cancer proliferation correlates with [F-18]fluorodeoxyglucose uptake by positron emission tomography. Clin Cancer Res 6:3837-3844

17. Schoder H, Noy A, Gonen M, Weng L, Green D, Erdi YE et al (2005) Intensity of 18 fluorodeoxyglucose uptake in positron emission tomography distinguishes between indolent and aggressive non-Hodgkin's lymphoma. J Clin Oncol 23:4643-4651

18. Juweid ME, Cheson BD (2005) Role of positron emission tomography in lymphoma. J Clin Oncol 23:4577-4580

19. Juweid ME, Stroobants S, Hoekstra OS, Mottaghy FM, Dietlein M, Guermazi A et al (2007) Use of positron emission tomography for response assessment of lymphoma: consensus of the imaging subcommittee of international harmonization project in lymphoma. J Clin Oncol 25:571-578

20. Lordick F, Ott K, Krause BJ, Weber WA, Becker K, Stein HJ et al (2007) PET to assess early metabolic response and to guide treatment of adenocarcinoma of the oesophagogastric junction: the MUNICON phase II trial. Lancet Oncol 8:797-805

21. Even-Sapir E, Parag Y, Lerman H, Gutman M, Levine C, Rabau M et al (2004) Detection of recurrence in patients with rectal cancer: PET/CT after abdominoperineal or anterior resection. Radiology 232:815-822

22. Veit-Haibach P, Kuehle CA, Beyer T, Stergar H, Kuehl H, Schmidt J et al (2006) Diagnostic accuracy of colorectal cancer staging with wholebody PET/CT colonography. JAMA 296:2590-2600

23. Amthauer H, Denecke T, Rau B, Hildebrandt B, Hunerbein M, Ruf J et al (2004) Response prediction by FDG-PET after neoadjuvant radiochemotherapy and combined regional hyperthermia of rectal cancer: correlation with endorectal ultrasound and histopathology. Eur J Nucl Med Mol Imaging 31:811-819

24. Kalff V, Duong C, Drummond EG, Matthews JP, Hicks RJ (2006) Findings on 18F-FDG PET scans after neoadjuvant chemoradiation provides prognostic stratification in patients with locally advanced rectal carcinoma subsequently treated by radical surgery. J Nucl Med 47:14-22

25. Gomori JM, Holland GA, Grossman RI, Gefter WB, Lenkinski RE (1988) Fat suppression by section-select gradient reversal on spin-echo MR imaging. Work in progress. Radiology 168:493-495

26. Boellaard R, van Lingen A, Lammertsma AA (2001) Experimental and clinical evaluation of iterative reconstruction (OSEM) in dynamic PET: quantitative characteristics and effects on kinetic modeling. J Nucl Med 42:808-817

27. Ho KC, Lin G, Wang JJ, Lai CH, Chang CJ, Yen TC (2009) Correlation of apparent diffusion coefficients measured by $3 \mathrm{~T}$ diffusion-weighted MRI and SUV from FDG PET/CT in primary cervical cancer. Eur J Nucl Med Mol Imaging 36:200-208

28. Downey RJ, Akhurst T, Ilson D, Ginsberg R, Bains MS, Gonen M et al (2003) Whole body 18FDG-PET and the response of esophageal cancer to induction therapy: results of a prospective trial. J Clin Oncol 21:428-432

29. Bos R, van Der Hoeven JJ, van Der Wall E, van Der Groep P, van Diest PJ, Comans EF et al (2002) Biologic correlates of (18) fluorodeoxyglucose uptake in human breast cancer measured by positron emission tomography. J Clin Oncol 20:379-387

30. Gu J, Yamamoto H, Fukunaga H, Danno K, Takemasa I, Ikeda M et al (2006) Correlation of GLUT-1 overexpression, tumor size, and depth of invasion with $18 \mathrm{~F}$-2-fluoro-2-deoxy-D-glucose uptake by positron emission tomography in colorectal cancer. Dig Dis Sci 5:2198-2205

31. Herholz K, Pietrzyk U, Voges J, Schroder R, Halber M, Treuer H et al (1993) Correlation of glucose consumption and tumor cell density in astrocytomas. A stereotactic PET study. J Neurosurg 79:853-858

32. Higashi K, Ueda Y, Yagishita M, Arisaka Y, Sakurai A, Oguchi M et al (2000) FDG PET measurement of the proliferative potential of nonsmall cell lung cancer. J Nucl Med 41:85-92

33. Kuwert T, Probst-Cousin S, Woesler B, Morgenroth C, Lerch H, Matheja P et al (1997) Iodine-123-alpha-methyl tyrosine in gliomas: correlation with cellular density and proliferative activity. J Nucl Med 38:1551-1555

34. Herneth AM, Guccione S, Bednarski M (2003) Apparent diffusion coefficient: a quantitative parameter for in vivo tumor characterization. Eur J Radiol 45:208-213

35. Lyng H, Haraldseth O, Rofstad EK (2000) Measurement of cell density and necrotic fraction in human melanoma xenografts by diffusion weighted magnetic resonance imaging. Magn Reson Med 43:828-836

36. Buck AK, Halter G, Schirrmeister H, Kotzerke J, Wurziger I, Glatting G et al (2003) Imaging proliferation in lung tumors with PET: 18F-FLT versus 18F-FDG. J Nucl Med 44:1426-1431 
37. Costelloe CM, Macapinlac HA, Madewell JE, Fitzgerald NE, Mawlawi OR, Rohren EM et al (2009) 18F-FDG PET/CT as an indicator of progression-free and overall survival in osteosarcoma. J Nucl Med 50:340-347

38. Guillem JG, Moore HG, Akhurst T, Klimstra DS, Ruo L, Mazumdar M et al (2004) Sequential preoperative fluorodeoxyglucose-positron emission tomography assessment of response to preoperative chemoradiation: a means for determining longterm outcomes of rectal cancer. $\mathrm{J}$ Am Coll Surg 199:1-7

39. Tateishi U, Gamez C, Dawood S, Yeung HW, Cristofanilli M, Macapinlac HA (2008) Bone metastases in patients with metastatic breast cancer: morphologic and metabolic monitoring of response to systemic therapy with integrated PET/CT. Radiology 247:189-196

40. Berger KL, Nicholson SA, Dehdashti F, Siegel BA (2000) FDG PET evaluation of mucinous neoplasms: correlation of FDG uptake with histopathologic features. AJR Am J Roentgenol 174:1005-1008

41. Kim BT, Kim Y, Lee KS, Yoon SB, Cheon EM, Kwon OJ et al (1998) Localized form of bronchioloalveolar carcinoma: FDG PET findings. AJR Am J Roentgenol 170:935-939

42. Higashi K, Nishikawa T, Seki H, Oguchi M, Nambu Y, Ueda Y et al (1998) Comparison of fluorine-18-FDG PET and thallium-201 SPECT in evaluation of lung cancer. J Nucl Med 39:9-15
43. Nasu K, Kuroki Y, Kuroki S, Murakami K, Nawano S, Moriyama N (2004) Diffusion-weighted single shot echo planar imaging of colorectal cancer using a sensitivity-encoding technique. Jpn J Clin Oncol 34:620-626

44. Daisne JF, Duprez T, Weynand B, Lonneux M, Hamoir M, Reychler H et al (2004) Tumor volume in pharyngolaryngeal squamous cell carcinoma: comparison at CT, MR imaging, and FDG PET and validation with surgical specimen. Radiology 233:93-100

45. Ashamalla H, Rafla S, Parikh K, Mokhtar B, Goswami G, Kambam S et al (2005) The contribution of integrated PET/CT to the evolving definition of treatment volumes in radiation treatment planning in lung cancer. Int J Radiat Oncol Biol Phys 63:1016-1023

46. Biehl KJ, Kong FM, Dehdashti F, Jin JY, Mutic S, El Naqa I et al (2006) 18F-FDG PET definition of gross tumor volume for radiotherapy of non-small cell lung cancer: is a single standardized uptake value threshold approach appropriate? J Nucl Med 47:1808-1812

47. Willinek WA, Gieseke J, von Falkenhausen M, Neuen B, Schild HH, Kuhl CK (2003) Sensitivity encoding for fast MR imaging of the brain in patients with stroke. Radiology 228:669-675

48. Takahara T, Imai Y, Yamashita T, Yasuda S, Nasu S, Van Cauteren M (2004) Diffusion weighted whole body imaging with background body signal suppression (DWIBS): technical improvement using free breathing, STIR and high resolution 3D display. Radiat Med 22:275-282 